\title{
nucture
}

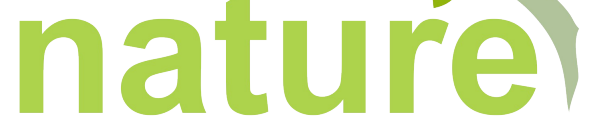

National Academic Journal of Architecture

\section{MUSEUM SEJARAH KABUPATEN BERAU DI TANJUNG REDEB KALIMANTAN TIMUR DENGAN PENDEKATAN ARSITEKTUR MODERN}

\author{
Wasilah ${ }^{1}$ Burhanuddin $^{2}$, Muhammad Rifai ${ }^{3}$ \\ Jurusan Arsitektur Fakultas Sains \& Teknologi UIN-Alauddin Makassar
}

\begin{abstract}
Abstrak - Tanjung Redeb sebagai Ibu kota Kabupaten Berau Kalimantan Timur memiliki banyak nilai sejarah dan budaya serta kekayaan alam dan. Tujuan Laporan perancangan ini adalah mendesain wadah Museum Sejarah Kabupaten Berau di Tanjung Redeb dengan Pendekatan Arsitektur Modern yang dapat memenuhi berbagai aspek di dalam desainnya, sehingga dapat menunjang kegiatan pelestarian, edukasi, penelitian dan rekreasi serta historial secara optimal sehingga menjadi monumen, sehingga masyarakat dapat menjiwai dan pada akhirnya akan menjadi kebanggaan masyarakat yang memiliki identitas daerah. Pendekatan Arsirtektur modern diterapkan pada fasad serta fasilitas-fasilas yang dapat menjadi menunjang serta menjadi icon atau landmark Kabupaten Berau.
\end{abstract}

Kata kunci: Museum, Kabupaten Barau, Tanjung Redab , Arsitektur Moderen. Icon, Landmark

\begin{abstract}
Cape Redeb as the capital of East Kalimantan Berau District has many historical and cultural values as well as natural resources the purpose of this report is to design museum historical Berau in Redab cape in architecture modern approaching that can fill the various aspects of in design, so can support conservation, education, research and recreation and history optimally that become a monument, so that people can recognize well and at last will be the pride of the community who have a regional identity. Architecture modern approach to the façade and also the supporting facilities that can become icon and landmark apllied Berau District
\end{abstract}

Keywords: Museum, Berau District, Redab Cape, Modern Architecture, Icon, Landmark

1Dosen Jurusan Teknik Arsitektur UIN Alauddin Makassar 2Dosen Jurusan Teknik Arsitektur UIN Alauddin Makassar

3 Alumni Jurusan Teknik Arsitektur UIN Alauddin Makassar Angkatan 2015 


\section{nucture}

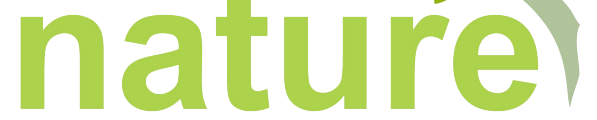

National Academic Journal of Architecture

\section{PENDAHULUAN}

Tanjung Redeb merupakan Ibu kota Kabupaten Berau Kalimantan Timur yang memiliki nilai-nilai sejarah dan budaya yang sangat menunjang keberadaan museum. Kabupaten ini memiliki luas wilayah $34.127,47 \mathrm{~km}^{2}$ dan berpenduduk sebesar kurang lebih 179.079 jiwa (hasil Sensus Penduduk Indonesia, 2010 dipetik digital tanggal 20 Maret 2015; http://id.wikipedia.org/wiki/Kabupaten_Berau). Tanjung Redeb memiliki potensi yang baik dari segi letak maupun kondisi dari orientasi yang mudah di jangkau dari daerah lain di Kalimantan Timur sendiri ataupun dari daerah di luar Kalimantan Timur karena tersedianya transportasi' baik di darat maupun di udar.

Tanjung Redeb memiliki sejarah yang keberadaannya hampir terlupakan oleh masyarakat karena tidak adanya sarana dan prasarana yang mendukung. Selain itu Kabupaten Berau masih minim akan desain bangunan yang bergaya arsitektur modern dari segi fasad. Untuk itu Kota Tanjung Redeb membutuhkan museum sebagai fasilitas pembelajaran yang mampu mempresentasikan sejarah dan kebudayaan yang akan mampu memacu masyarakat untuk lebih mencintai sejarah dan kebudayaan Tanjung Redeb.

Konsep modern diadopsi berdasarkan pertimbangan minat masyarakat terhadap benda bersejarah serta fungsi museum yang mampu menjadi memorial kejadian masa lampau. Hal ini harapkan mampu memberikan kesan yang berbeda pada bangunan, dimana secara eksterior masyarakat di bawa ke nuansa modern (masa depan) dan sebaliknya ketika masuk ke interior ruang, masyarakat merasakan nilainilai masa lampau.

Benda-benda bersejarah masyarakat Barau antara lain:

1. Meriam pijitan merupakan salah satu alat peperangan yang di gunakan pada kerajaan

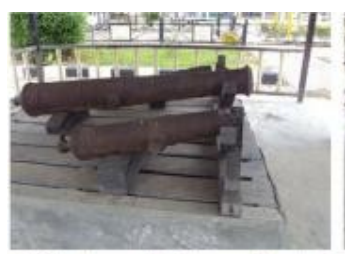

$\mathbf{N}$

2. Piring makan keramik china dari dinasti song abad 12-13 yang terbuat dari tanah liat dan mempunyai tekstur sangat halus di gunakan para raja- raja Kabupaten Berau sebagai peralatan makan sebagai salah satu koleksi pajangan

3. Piring makan keramik china dari dinasti yuan abad 13-14 Yuan masa inovasi dalam produksi keramik yang menggunakan motif dekoratif baru dan bentuk kapal berasal dari logam Timur Dekat yang gunakan para raja-raja Kabupaten Berau sebagai peralatan makan dan sebagai salah satu koleksi pajangan 


\section{nucture}

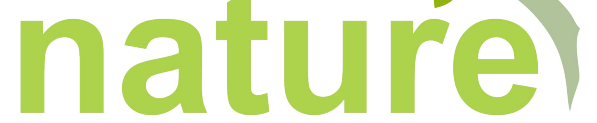

National Academic Journal of Architecture

4. Piring makan keramik dari Korea yang digunakan para raja-raja Kabupaten Berau sebagai peralatan makan dan sebagai salah satu koleksi pajangan

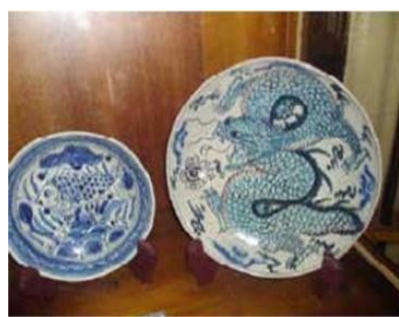

Gambar. Piring Makan

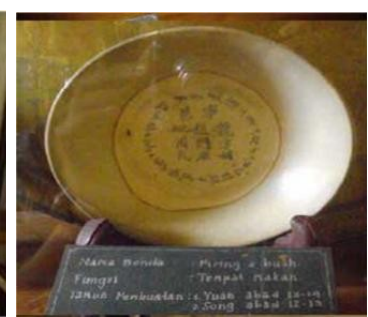

Keramik Korea

(Sumber: Olah Data Lapangan, 2015)

5. Piring makan keramik dari Belanda yang digunakan para raja-raja Kabupaten Berau sebagai peralatan makan dan sebagai salah satu koleksi pajangan

6. Piring makan keramik dari Arab yang digunakan para raja-raja Kabupaten Berau sebagai peralatan makan dan sebagai salah satu koleksi pajangan

7. Guci sri rejeki gunakan para raja-raja Kabupaten Berau sebagai tempat penyimpanan madu dan air bersih persediaan minum para raja-raja

8. Mangkok yang gunakan para raja-raja Kabupaten Berau sebagai tempat penyimpanan koe atau wadai kering

9. Keramik China yang gunakan para raja-raja Kabupaten Berau sebagai koleksi atau perhiasan pajangan
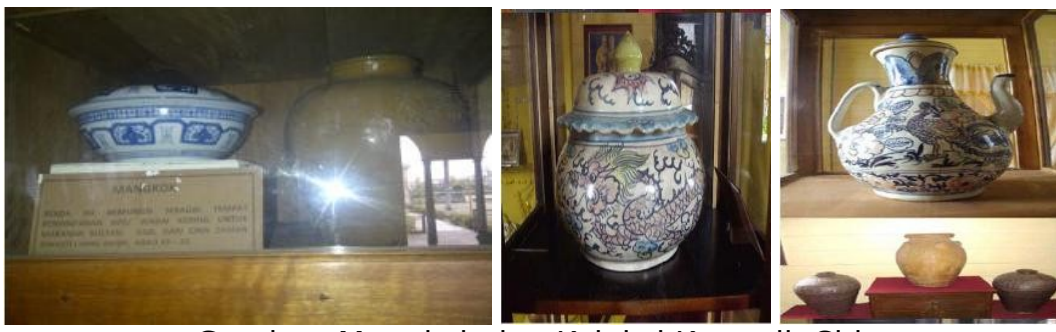

Gambar. Mangkok dan Koleksi Keramik China

(Sumber: Olah Data Lapangan, 2015)

10. Alat pembantu kelahiran yang digunakan para raja-raja Kabupaten Berau sebagai alat pembantu untuk memperlancar atau mendapatkan keturunan

11. Dipan merupakan tempat melangsungkan kelahiran putra putri para raja Kabupaten Berau

12. Tahta merupakan tempat duduk Sultan dan Ibu permaisuri Kabupaten Berau

13. Pedang pusaka merupakan salah satu alat peperangan yang di gunakan pada kerajaan-kerajaan Kabupaten Berau.

14.Jambang atau tameng di gunakan pada saat peperangan yang berfungsi sebagai alat perlindungan dari senjata tajam dan juga sebagai penanda sebagai masyarakat Kabupaten Berau. 


\section{nucture}

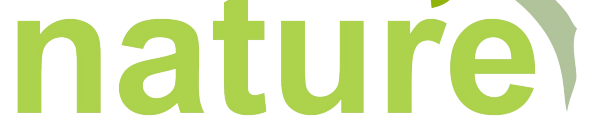

National Academic Journal of Architecture
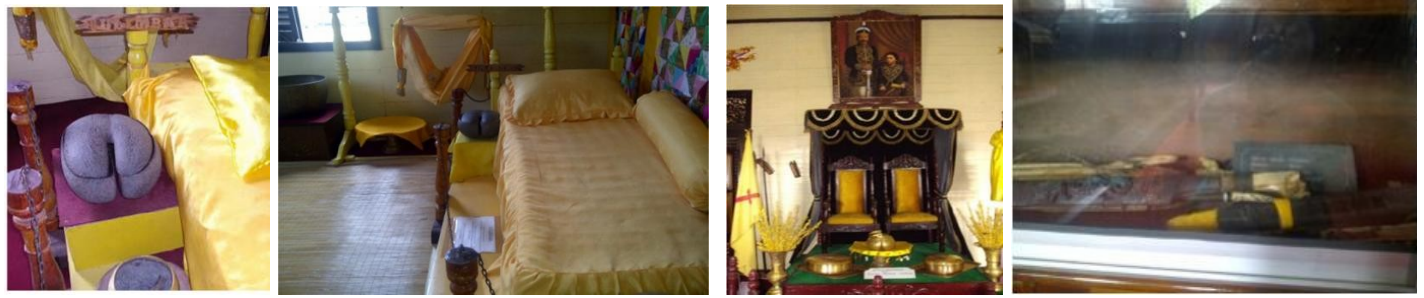

Gambar. Alat Pembantu Kelahiran, Dipan, Tahta, dan Pedang Pusaka

(Sumber: Olah Data Lapangan, 2015)

Melalui pertimbangan di atas maka desain Museum Sejarah Kabupaten Berau di Tanjung Redeb merupakan suatu wadah yang diharapkan dapat menjadi sarana edukasi mengenai sejarah Kabupaten Berau di Tanjung Redeb. Fasilitas-fasilitas modern serta desain perancangan museum dengan pendekatan Arsitektur Modern, terutama pada fasad serta bentuk bangunan yang mengkombinasikan antara bentuk kotak dan lengkung dengan menggunakan material kaca dan struktur baja di harapkan sesuai di terapkan pada Museum Sejarah Kabupaten Berau di Tanjung Redeb, serta dapat menjadi icon atau landmark Kabupaten Berau sehingga menarik minat masyarakat lokal maupun interlokal untuk mengunjungi Museum Sejarah kota Tanjung Redeb.

\section{METODE PERANCANGAN}

Menggunakan tahapan pengumpulan data melalui observasi, dan studi literatur, kemudian dianalisa dengan mengidentifikasikan unsur yang menunjang, mengelompokkan dan mengaitkan antara permasalahan dan untuk ditransformasikan ke dalam konsep perencanaan sehingga mendapatkan hasil yang maksimal dalam bentuk perencanaan fisik bangunan museum sesuai dengan tujuan .

\section{KONSEP DESAIN}

\section{A. Konsep Tata Lansekap}

Tata lansekap terinspirasi dari benda-benda bersejarah yang kemudian diadopsi sebagai pola site bangunan. Selanjutnya untuk pertimbangan orientasi bangunan didapatkan melalui pertimbangan jalan utama yang disesuaikan dengan fungsi awal tapak yaitu sebagai terminal bus. Sehingga melalui pertimbangan tersebut didapatkan bentuk site mengikuti pola kawasan yang kemudian diorientasikan memanjang dari Timur Laut ke Barat Daya.
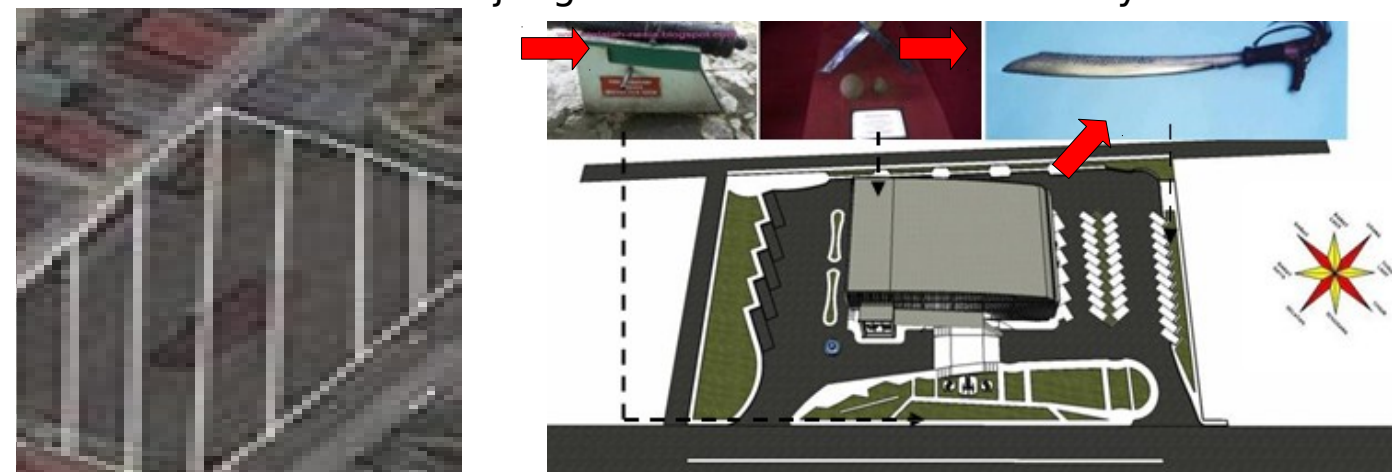

Gambar. Analisis Tata Lansekap Kawasan Perancangan

(Sumber : Olah Desain 2015) 


\section{nucture}

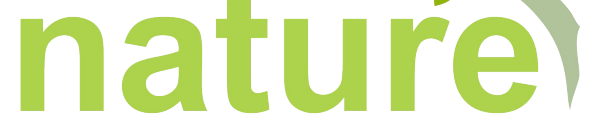

National Academic Journal of Architecture

Desain tapak museum sejarah lebih mengutamakan ruang hijau,sehingga dapat meminimalisir aktifitas yang menghasilkan tingkat polusi tinggi.

Sirkulasi dibedakan atas sirkulasi pejalan kaki dan sirkulasi kendaraan. Sirkulasi pejalan kaki dibuat dengan pertimbangan kemudahan pencapai terhadap tapak dan bangunan museum. Sedangkan sirkulasi kendaraan melalui petimbangan kondisi lingkungan serta existing tapak.
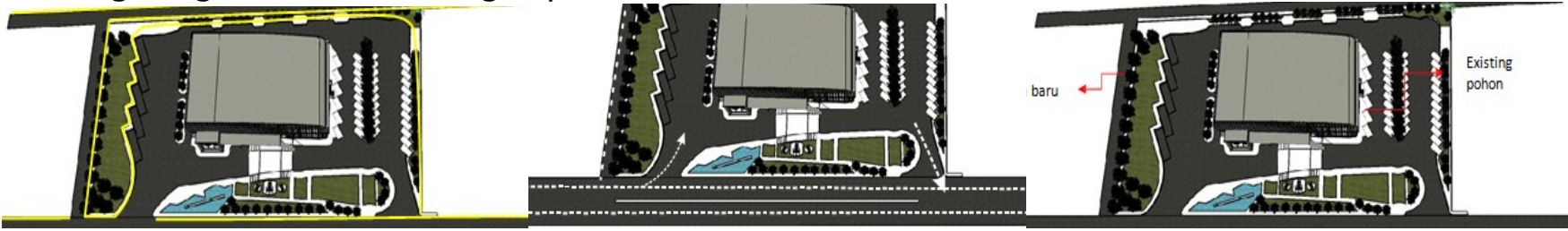

Sirkulasi Pejalan Kaki, Sirkulasi Kendaraan, dan Tata Hijau

(Sumber : Olah Desain 2015)

Desain museum merupakan bangunan massa tunggal dengan petimbangan pada fungsi museum, memudahkan pengontrolan materi koleksi dan sirkulasi pengunjung, serta memberikan keamanan yang lebih terjamin dan pengelompokkan kegiatan dapat dicapai secara vertikal.

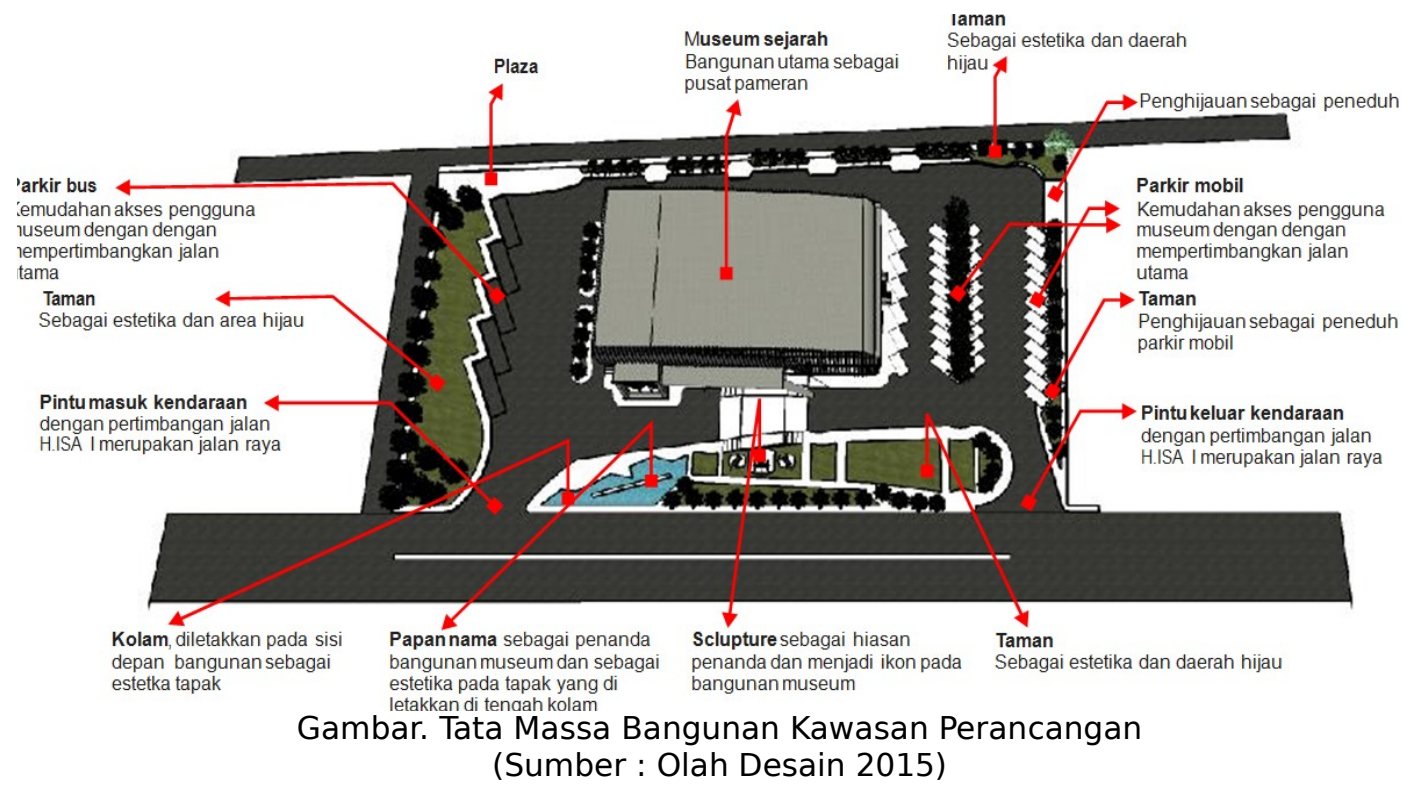

\section{B. Konsep Desain Bangunan}

Bentuk bangunan, memaadukan antara bentuk kotak dan lengkung yang mengadopsi dari benda sejarah berupa tempat rokok raja (bentuk bangunan), koleksi mata uang (fasad kotak), dan meriam pijitan (kisi-kisi fasad). 


\section{nucture naturel}

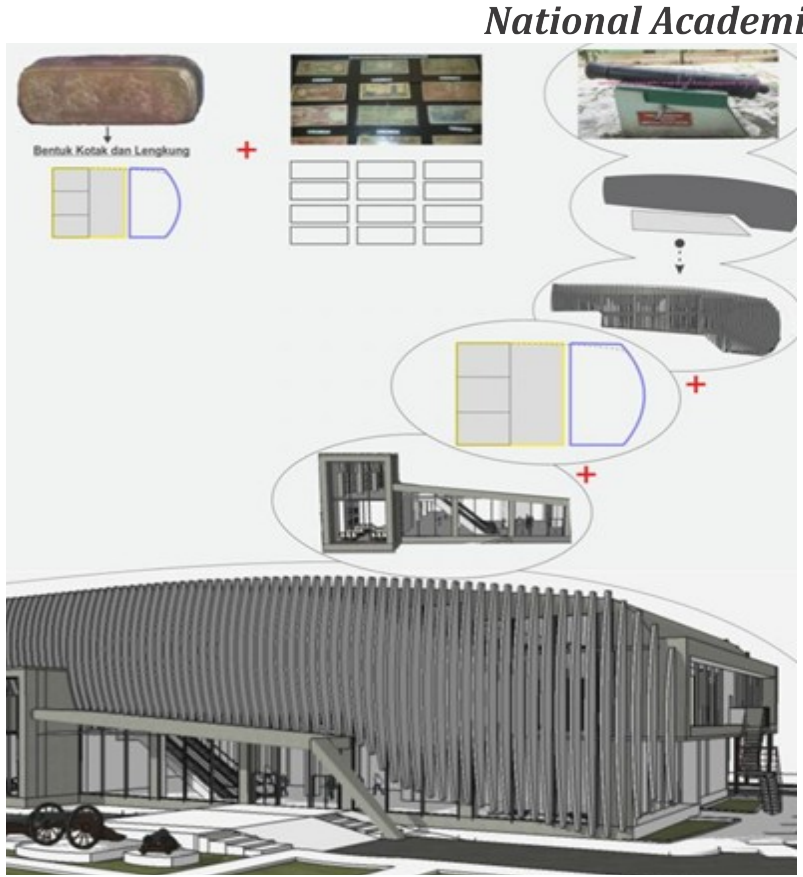

Gambar: Transformasi bentuk desain bangunan museum sejarah (Sumber : Olah Desain 2015)

\section{Konsep Layout Ruang}

Penataan layout ruang berdasarkan pada jenis dan fungsi ruang dimana akses ruang di bedakan berdasarkan pengelompokan zona-zona ruang.

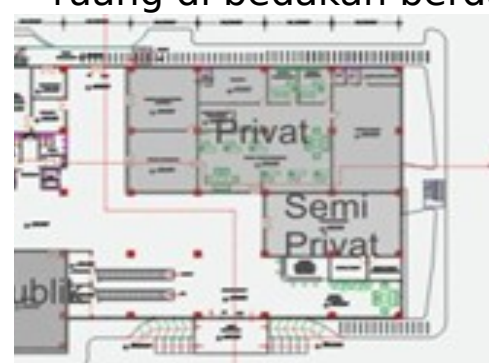

Denah Lantai I

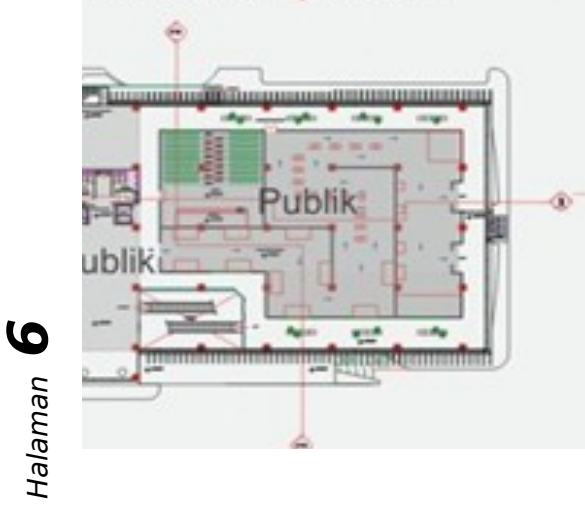

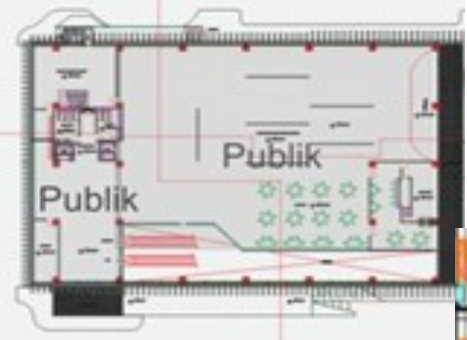

\section{Denah Lantai II}

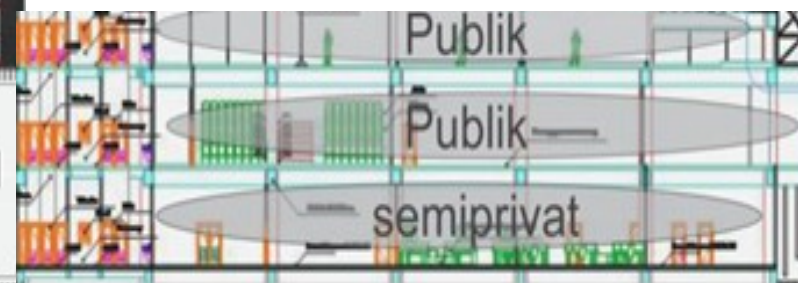

Gambar: Layout ruang (Sumber : Olah Desain 2015) 


\section{nucture naturel}

National Academic Journal of Architecture

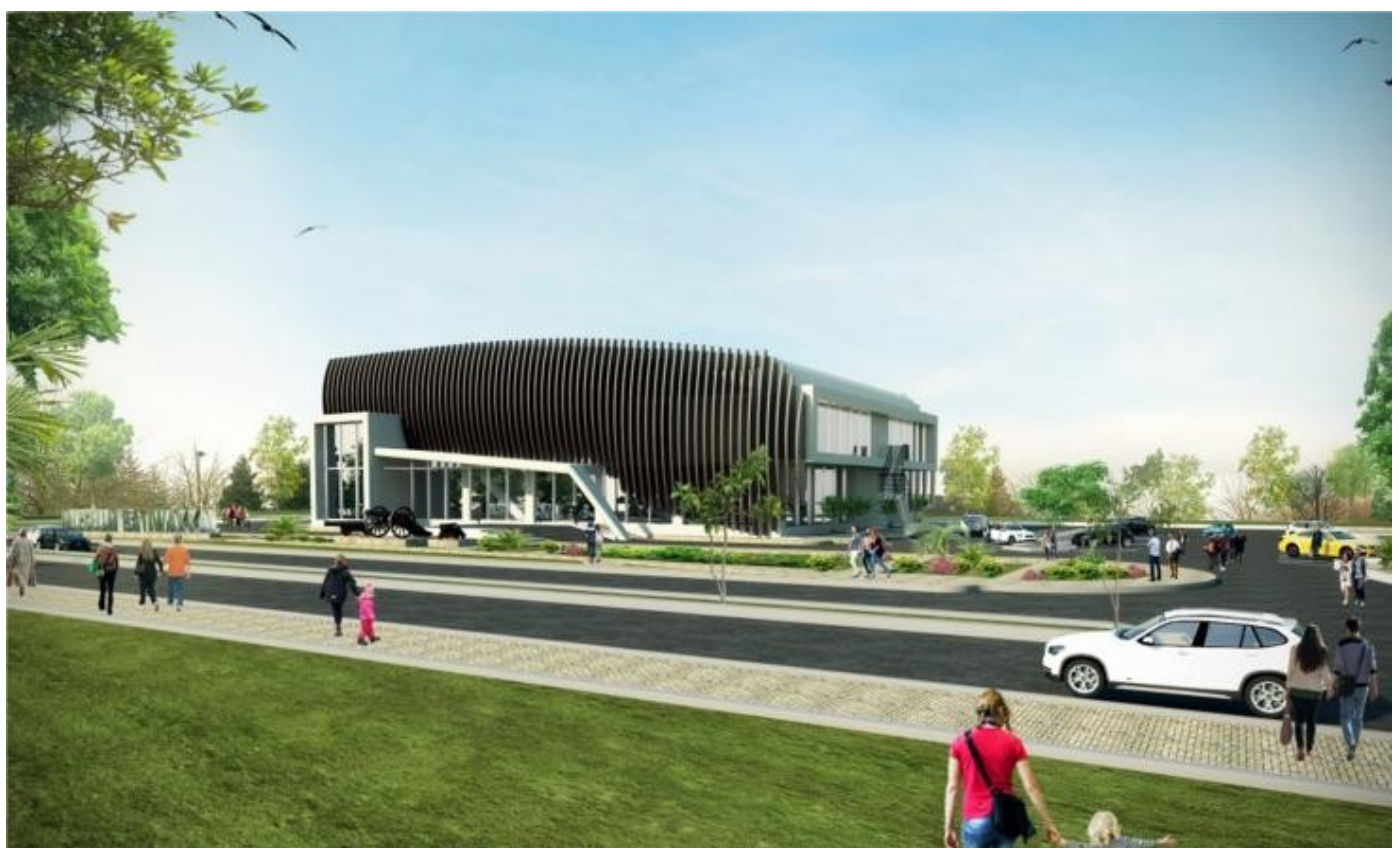

Gambar: Desain Perespektif

(Sumber : Olah Desain 2015)

\section{Konsep Struktur dan Material}

Sub struktur yang di gunakan yaitu pondasi tiang pancang sebagai struktur kolom utama dan pondasi poer sebagai pondasi skat ruangan, sedangkan pada super struktur, lantai yang digunakan menggunakan material berupa keramik serta dinding massif yang berfungsi sebagai dinding pembagi ruang yang terbuat dari material susunan bata, sedangkan material kaca tempered, kaca spider dan struktur baja digunakan pada fasade, dan upper struktur menggunakann rangka batang. 


\section{nucture naturel}

National Academic Journal of Architecture

\section{SUPER STRUKTUR}

UPPER STRUKTUR

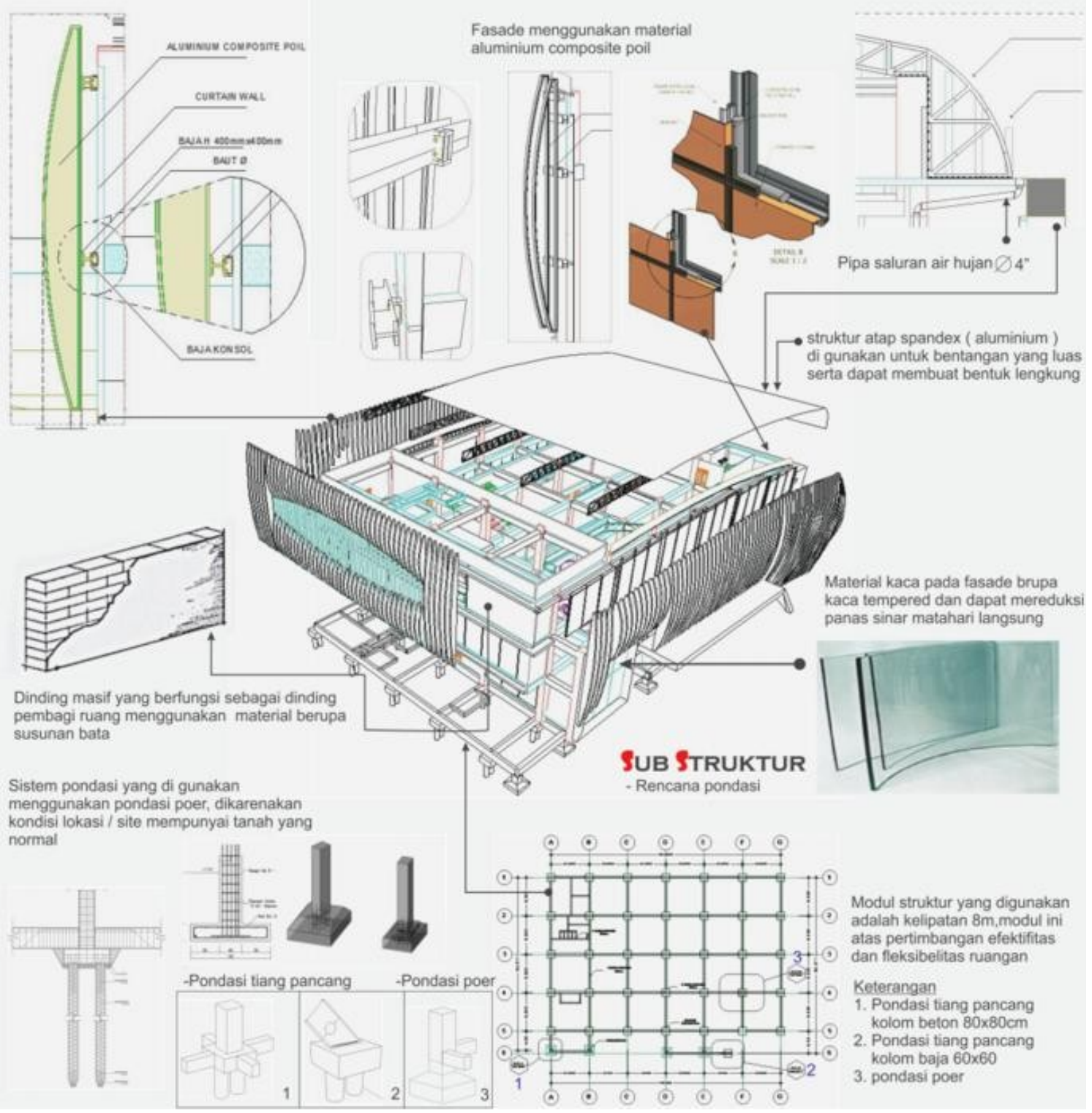

Gambar. Struktur dan Material

(Sumber : Olah Desain 2015)

$\infty$

$\frac{5}{\frac{1}{\pi}}$

\section{KESIMPULAN}

Kabupaten Berau membutuhkan museum sejarah agar nilai budaya Masyarakat Barau ini masih terjaga dan terawat serta menjadi bahan edukasi untuk generasi yang 


\section{nucture naturel}

National Academic Journal of Architecture

akan datang.. Bentuk bangunan fasad yaitu memadukan antara bentuk kotak dan lengkung yang mengadopsi dari benda sejarah berupa tempat rokok raja (bentuk bangunan), koleksi mata uang (kotak), dan meriam pijitan (kisi-kisi).

\section{DAFTAR PUSTAKA}

Kusuma, Ega. (2013). Pengertian Sejarah Menurut Para Ahli (Terlengkap dan Terbaru). http://psugen12.blogspot.com/2013/07/pengertian-sejarah-menurut- para-ahli.html, diakses digital tanggal 07 April 2015

Lestari, Annisa putri. (2015). ARSITEKTUR MODERN. http://www.academia.edu/10097828/Arsitektur_Modern, diakses digital tanggal 29 Juni 2015

Mallu, Akhmad Syahrani. (2012) Pusat Wisata Pantai Di Makassar dengan Pendekatan Arsitektur Modern. Acuan Perancangan, Universitas Islan Negeri Alauddin Makassar, Makassar.

Nazira, Hilwa. (2013). Penerapan Al-Quran dalam Konsep Arsitektur. http://hilwanazira.blogspot.com/2013/12/arsitektur-dalam-ayat-al-quran.html, diakses digital tanggal 20 Maret 2015;

Prasetyo, Harry. (2013) 6 Perpustakaan Dengan Arsitektur Modern. http://www.rumahku.com/berita/read/6perpustakaan-dengan-arsitektur- modern-406473\#.VSc-qvmUe7w, diakses digital tanggal 10 April 2015

Rosenfield, Karissa. (2012) Louvre Lens / SANAA. http://www.archdaily.com/312978/louvre-lens-sanaa/, diakses digital tanggal 07 April 2015

Sasmita, Kapindo. (2008) Desain dan Produk Gaya Bauhaus. http://www.sasmitaarsitek.com/desain-dan-produk-gayabauhaus/, diakses digital tanggal 10 April 2015

Sihab M.Quraish. (2002). Tafsir Al-Misbah. Jakarta: Lentera Hati

Vhyvhi (2011). ELEMEN-ELEMEN DASAR DALAM PERANCANGAN ARSITEKTUR. https://ingo1.wordpress.com/2011/06/16/elemen- \%E2\%80\%93-elemen-dasar-dalam-perancangan-arsitektur/, diakses digital tanggal 29 Juni 2015

Webo, Uii (2013).PRINSIP-PRINSIP DESAIN DALAM ARSITEKTUR.

http://arsitekpemuda.blogspot.com/2013/03/prinsip-prinsip-desain-dalam- arsitektur.html diakses digital tanggal 29 Juni 2015

Zakaria, Mohammad. (2011). Ini Bukan Blog Arsitektural. http://belajaritutiadaakhir.blogspot.com/2011/08/museum-di-indonesia.html, diakses digital tanggal 20 Maret 2015 